\title{
Use of Magnetic Resonance Imaging to Identify Outcome Predictors of Caudal Epidural Steroid Injections for Lower Lumbar Radicular Pain Caused by a Herniated Disc
}

\author{
Sung Oh Cha, $\mathrm{MD}^{1,2}$, Chul Hoon Jang, $\mathrm{MD}^{1,2}$, Jin Oh Hong, $\mathrm{MD}^{1,2}$, \\ Joon Sang Park, $\mathrm{MD}^{1,2}$, Jung Hyun Park, $\mathrm{MD}, \mathrm{PhD}^{1,2}$ \\ ${ }^{1}$ Department of Rehabilitation Medicine, Gangnam Severance Hospital, Seoul; \\ ${ }^{2}$ Rehabilitation Institute of Neuromuscular Disease, Yonsei University College of Medicine, Seoul, Korea
}

\begin{abstract}
Objective We used lumbar magnetic resonance image (MRI) findings to determine possible outcome predictors of a caudal epidural steroid injection (CESI) for radicular pain caused by a herniated lumbar disc (HLD).

Methods Ninety-one patients with radicular pain whose MRI indicated a HLD were enrolled between September 2010 and July 2013. The CESIs were performed using ultrasound (US). A responder was defined as having complete relief or at least a $50 \%$ reduction of pain as assessed by the visual analog scale (VAS) and functional status on the Roland Morris Disability Questionnaire (RMDQ); responder (VAS $n=61$, RMDQ $n=51$ ), and non-responder (VAS $\mathrm{n}=30$, RMDQ $\mathrm{n}=40$ ). MRI findings were analyzed and compared between the two groups with regard to HLD level, HLD type (protrusion or exclusion), HLD zone (central, subarticular, foraminal, and extraforaminal), HLD volume (mild, moderate, or severe), relationship between HLD and nerve root (no contact, contact, displaced, or compressed), disc height loss (none, less than half, or more than half), and disc degeneration grade (homogeneous disc structure or inhomogeneous disc structure-clear nucleus and height of intervertebral disc).

Results A centrally located herniated disc was more common in the responder group than that in the nonresponder group. Treatment of centrally located herniated discs showed satisfactory results. (VAS $\mathrm{p}=0.025$, RMDQ $\mathrm{p}=0.040$ ). Other factors, such as HLD level, HLD type, HLD volume, relationship to nerve root, disc height loss, and disc degeneration grade, were not critical.

Conclusion The HLD zone was significant for pain reduction after CESI. A centrally located herniated disc was a predictor of a good clinical outcome.
\end{abstract}

Keywords Radicular pain, Epidural injections, Caudal, Ultrasound, Magnetic resonance image

(c) This is an open-access article distributed under the terms of the Creative Commons Attribution Non-Commercial License (http://creativecommons.org/ licenses/by-nc/3.0) which permits unrestricted noncommercial use, distribution, and reproduction in any medium, provided the original work is properly cited. Copyright $\odot 2014$ by Korean Academy of Rehabilitation Medicine 


\section{INTRODUCTION}

Lumbar radicular pain is commonly encountered during medical rehabilitation treatment. Lumbar radicular pain can be caused by a herniated lumbar disc (HLD), spinal stenosis, spinal disorder, etc. The development of severe lumbar radicular pain and sciatica depends on both mechanical compression and concomitant chemical irritation of the nerve root caused by disc material [1-3]. Therefore, local application of corticosteroids to the compressed and inflamed nerve root is a reasonable treatment option.

The transforaminal, interlaminar, and caudal routes are the three principal techniques available to deliver medication into the epidural space. Caudal epidural steroid injections (CESIs) are the safest and easiest blocking method with the least risk for inadvertent dural puncture, despite the need for a relatively high volume [4].

Although CESI is a good method for long-term pain-relief in many patients, it is not effective for everyone. This result suggests that a variety of structural, environmental, and genetic causes [5] should be considered before implementing a CESI but this is difficult in practice. Therefore, we determined whether the effects of a CESI can be predicted in a simple way by using objective images, such as those provided by magnetic resonance imaging (MRI).

\section{MATERITALS AND METHODS}

\section{Patient selection}

We retrospectively analyzed the medical records of 91 patients (30 males and 61 females; age, 17-79 years) with lumbar radicular pain who received a CESI and were hospitalized in the Department of Rehabilitation Medicine between December 2010 and July 2013. We investigated patients with HLD for whom physical therapy in the outpatient department or at other hospitals for $>2$ weeks was ineffective and who had an MRI $<3$ months prior to their CESI treatment. All patients had undergone MRI scans confirming the existence of lumbar disc-related pain (herniation) that was expected to improve following a CESI. A positive result on the Straight Leg Raise Test was not mandatory for a patient to be enrolled in the study, as it is well accepted that degenerative changes do not necessarily correlate with pain generation [6]. The exclusion criteria were 1) motor weakness due to radiculopathy or cauda equina injury, 2) no prior surgery, and 3) a medical history of steroid injection treatment within 6 months.

\section{Injection technique}

All CESIs and ultrasonography (US) examinations were performed by a physician with more than 10 years experience. US was provided by an Accuvix V10 (Samsung Medison, Seoul, Korea). After placing a pillow on the lower abdomen, patients were placed in a prone position for the CESI procedure. After positioning the US transducer on the transverse midline of the sacral hiatus, a US view of the sacral hiatus was identified. The diameter between two sacral cornua was measured. Next, the depth of the hiatus from the skin was measured through a longitudinal US view. A 23-gauge spinal needle was advanced while facing the bevel down at a $45^{\circ}$ angle toward the sacral canal and positioned between the two cornua. Needle position was reconfirmed using the 'pop' or 'give' feeling when the needle penetrated a sacrococcygeal ligament. The needle was advanced and redirected cephalad, horizontal, and parallel for further advancement. A sufficient volume of fluid was injected consisting of interspersed $8 \mathrm{~mL}$ normal saline, $2 \mathrm{~mL} 10 \mathrm{mg}$ dexamethasone, and $20 \mathrm{~mL}$ lidocaine. An inhalation test was used to verify that there was no blood.

\section{Review of the MRI findings and clinical data}

CESI effectiveness was evaluated using the visual analogue scale (VAS) and the Roland Morris Disability Questionnaire (RMDQ). The VAS is a measurement instrument that assesses a characteristic or attitude that ranges across a continuum of values and cannot easily be measured directly [7]. A VAS is usually a horizontal line, $100 \mathrm{~mm}$ in length, anchored by word descriptors at each end [7]. The patient marks the point on the line that they feel represents their perception of their current state [7]. The VAS score is determined by measuring in $\mathrm{mm}$ from the left side of the line to the point marked by the patient [7]. The RMDQ is a self-administered outcome measure of disability where greater levels of disability are reflected by higher numbers on a 24-point scale $[8,9]$. Patients were asked to read a list of 24 sentences and place a tick against appropriate questions based on how they feel each sentence described them today $[8,9]$. If the sentence does not describe their symptoms, the patients were asked to leave the space next to the sentence blank $[8,9]$. 
'Responder' was defined as a patient with a VAS score that decreased by $>50 \%$ or an RMDQ that improved by $>50 \%$. 'Non-responder' referred to a patient whose VAS score did not decrease by $>50 \%$ or the RMDQ did not improve by $>50 \%$.

One radiologist analyzed the MRI images without previous knowledge of patient symptoms. The MRI images were classified by HLD type, HLD zone, HLD volume, relationship of the HLD to nerve roots, disc height loss, and disc degeneration grade. Classification of HLD type, HLD zone, and HLD volume followed the standards used by the American Society of Spine Radiology, the American Society of Neuroradiology, and the North American Spine Society [10]. HLD type was divided into 'protrusion' and 'exclusion', and HLD zone consisted of 'central', 'subarticular, 'foraminal', and 'extraforaminal' (Figs. 1, 2). HLD volume was sorted into 'mild, 'moderate', and 'severe'. When the volume of a herniated disc accounted for onethird of the canal, it was categorized as 'mild'; 'moderate' was defined as a case when a herniated disc covered onethird to two-thirds of the canal volume; and 'severe' was used when a herniated disc's volume accounted for more than two-thirds of the canal. To investigate the relationship between the HLD and nerve roots, we examined whether the prominent HLD contacted nerve roots, and whether the nerve roots were displaced and compressed

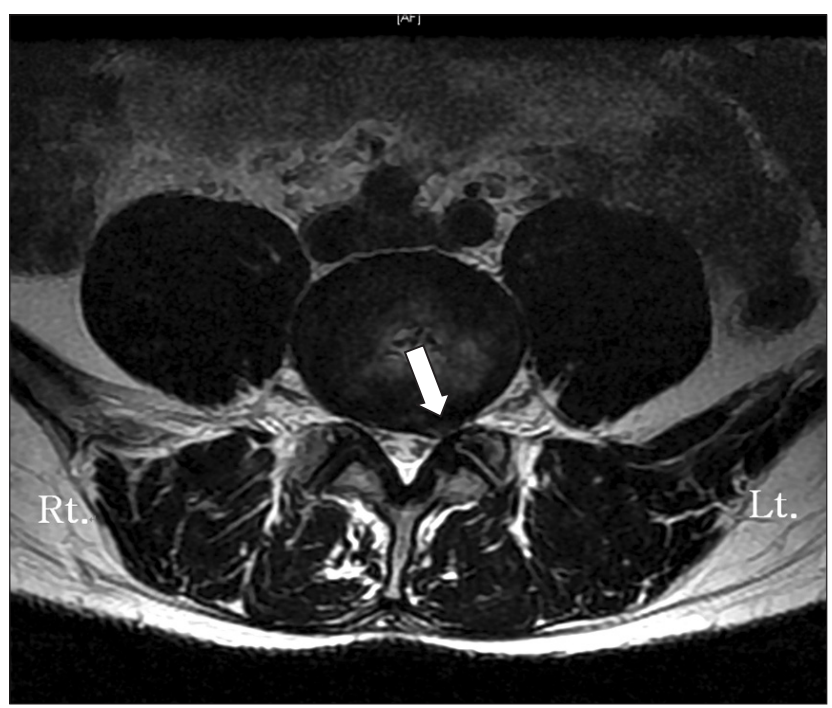

Fig. 1. A 51-year-old woman in the responder group after a caudal epidural injection. Central disc herniation was noted at the L5/S1 level on magnetic resonance imaging, with right L5 nerve root contact (white arrow). Rt., right side; Lt., left side. by the HLD [11]. Degeneration grade was categorized into five stages by looking at T2 MRI images [12]. This was divided into two categories: grades 1,2, and 3 vs. grades 4 and 5. The level of disc height loss was defined as 'none', 'decrease by $<50 \%$, and 'decrease by $>50 \%$ ' [10].

\section{Statistical analysis}

The characteristics of age, sex, duration of symptom attack, and MRI findings between responders and nonresponders were evaluated by the Mann-Whitney U-test and the chi-square test. Logistic regression analysis was performed to assess the relationship between the factors. Patient age, sex, duration of symptoms, HLD type, HLD zone, HLD volume, relationship between HLD and nerve roots, disc height loss, and disc degeneration grade were included in the analysis. The effect of the CESI was obtained through an adjusted odds ratio. The statistical analysis was performed with the SPSS Korean ver. 20.0 statistical package for Windows (IBM SPSS Inc., Armonk, NY, USA). A p-value $<0.05$ was considered significant.

\section{RESULTS}

The VAS and RMDQ for patients with lumbar radicular treated with CESI showed that the HLD zone was related to the effectiveness of CESI (VAS $p=0.025$, RMDQ

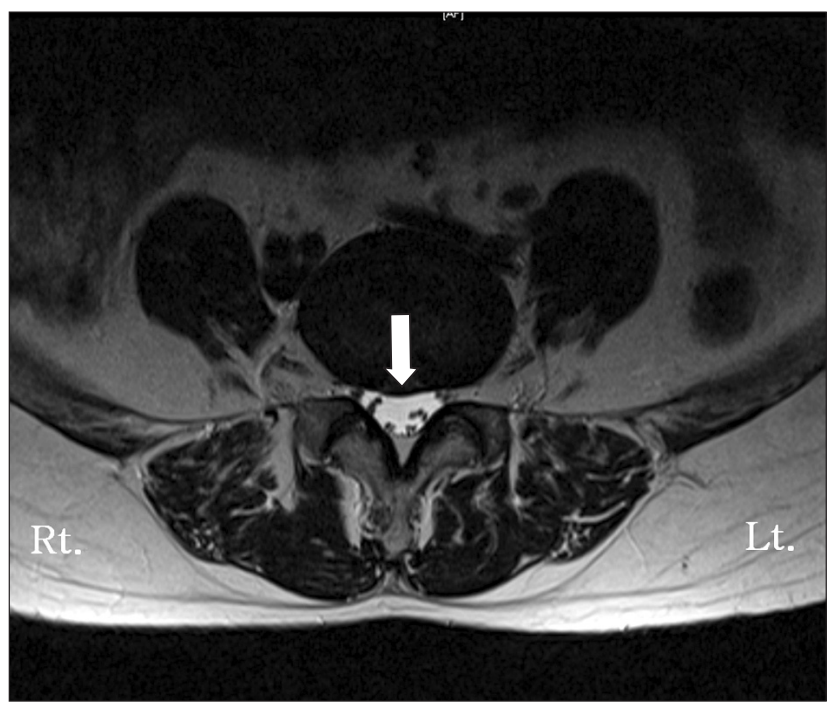

Fig. 2. A 49-year-old woman in the non-responder group after a caudal epidural injection. Left foraminal disc herniation was noted at the L5/S1 level on magnetic resonance imaging, with left L5 nerve root compression (white arrow). Rt., right side; Lt., left side. 
$\mathrm{p}=0.040$ ). No significant differences were observed between responders and non-responders for HLD level, HLD type, HLD volume, nerve root relationship with HLD, disc height loss, or disc degeneration (Tables 1, 2).

Most HLDs (87.9\%) were located in the central and subarticular zones, and they were more likely to be positioned in the central zone (46.2\%) than in the subar-

Table 1. Multivariate analysis of factors associated with the VAS score after caudal epidural injection

\begin{tabular}{lccc}
\hline \multicolumn{1}{c}{ Variable } & Adjusted OR & $\mathbf{9 5 \%} \mathbf{C I}$ & p-value \\
\hline HLD level & & & \\
L4/5 & 1.00 & - & \\
L5/S1 & 1.07 & $0.15-7.78$ & 0.95 \\
L4/5/S1 & 0.56 & $0.15-2.07$ & 0.38 \\
\hline HLD type & & & \\
Protrusion & 1.00 & & \\
\hline Extrusion & 0.74 & $0.06-8.99$ & 0.81 \\
\hline HLD zone & & & \\
\hline Central & 1.00 & - & \\
\hline Subarticular & 0.22 & $0.06-0.90$ & 0.04 \\
\hline Foraminal & 0.05 & $0.01-0.35$ & 0.00 \\
\hline Extraforaminal & - & - & 1.00 \\
\hline HLD volume & & & \\
Mild & 1.00 & - & \\
\hline Moderate & 0.51 & $0.13-1.97$ & 0.33 \\
\hline Severe & 0.38 & $0.07-2.07$ & 0.26 \\
\hline Nerve root - HLD & & & \\
\hline No contact & 1.00 & - & \\
\hline Contact & 0.20 & $0.02-2.04$ & 0.18 \\
\hline Displacement & 0.83 & $0.08-8.28$ & 0.88 \\
\hline Compression & 1.32 & $0.14-12.18$ & 0.81 \\
\hline Disc height loss & & & \\
\hline None & 1.00 & - & \\
\hline Less than half & 0.76 & $0.24-2.45$ & 0.65 \\
\hline More than half & 1.72 & $0.23-13.16$ & 0.60 \\
\hline Disc degeneration & & & \\
\hline Grade 1, 2, 3 & 1.00 & - & \\
\hline Grade 4, 5 & 1.09 & 4.17 & 0.90 \\
\hline
\end{tabular}

HLD, herniated lumber disc; VAS, visual analogue scale; $\mathrm{OR}$, odds ratio; $\mathrm{CI}$, confidence interval.

ORs are for at least $50 \%$ reduction in pain (VAS), and each variable was adjusted for the other variables.

p-values and 95\% CIs were calculated using the Wald chi-square test. ticular zone (Table 3). The VAS and RMDQ scores of the responders tended to increase at a closer proximity to the central zone. According to the logistic-regression analysis, HLD zonation was the only independent predictor. The CESI was effective for $22 \%$ of the HLDs in the subarticular zone and $5 \%$ in the foraminal zone compared to the central zone. Effectiveness in the extraforaminal zone

Table 2. Multivariate analysis of factors associated with the RMDQ score after caudal epidural injection

\begin{tabular}{cccc}
\hline Variable & Adjusted OR & $\mathbf{9 5 \%}$ CI & p-value \\
\hline HLD level & & &
\end{tabular}

\begin{tabular}{llcc} 
L4/5 & 1.00 & - & \\
\hline L5/S1 & 0.79 & $0.14-4.42$ & 0.79 \\
\hline L4/5/S1 & 0.58 & $0.18-1.91$ & 0.37
\end{tabular}

\section{HLD type}

$\begin{array}{llcl}\text { Protrusion } & 1.00 & - & \\ \text { Extrusion } & 0.97 & 0.12-8.013 & 0.98\end{array}$

HLD zone

Central

1.00

Subarticular

0.67

$0.22-2.08$

0.49

Foraminal

0.12

0.02-0.88

0.04

Extraforaminal

$-$

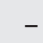

1.00

HLD volume

$\begin{array}{llcc}\text { Mild } & 1.00 & - & \\ \text { Moderate } & 0.42 & 0.13-1.40 & 0.16 \\ \text { Severe } & 0.64 & 0.13-3.21 & 0.58\end{array}$

Nerve root - HLD

$\begin{array}{llcc}\text { No contact } & 1.00 & - & \\ \text { Contact } & 0.46 & 0.07-3.10 & 0.43 \\ \text { Displacement } & 1.28 & 0.18-9.32 & 0.81 \\ \text { Compression } & 1.33 & 0.20-9.02 & 0.77\end{array}$

Disc height loss

$\begin{array}{llcc}\text { None } & 1.00 & - & \\ \text { Less than half } & 1.46 & 0.50-4.28 & 0.50 \\ \quad \text { More than half } & 6.63 & 0.98-44.59 & 0.05 \\ \begin{array}{l}\text { Disc degeneration } \\ \text { Grade 1, 2, 3 }\end{array} & 1.00 & - & \\ \text { Grade 4, 5 } & 1.21 & 0.35-4.19 & 0.77\end{array}$

HLD, herniated lumber disc; RMDQ, Roland Morris Disability Questionnaire; OR, odds ratio; CI, confidence interval.

ORs are for at least $50 \%$ reduction in pain (VAS), and each variable was adjusted for the other variables. p-values and 95\% CIs were calculated with the Wald chisquare test. 
Table 3. Magnetic resonance imaging findings related to outcome after caudal epidural steroid injections: responders vs. non-responders

\begin{tabular}{|c|c|c|c|c|}
\hline & \multicolumn{2}{|c|}{ VAS } & \multicolumn{2}{|c|}{ RMDQ } \\
\hline & Responders $(n=61)$ & Non-responders $(\mathrm{n}=\mathbf{3 0})$ & Responders ( $n=51)$ & Non-responders $(n=40)$ \\
\hline \multicolumn{5}{|l|}{ HLD level } \\
\hline $\mathrm{L} 4 / 5$ & $37(62.7)$ & $22(37.3)$ & $34(53.1)$ & $30(46.9)$ \\
\hline $\mathrm{L} 5 / \mathrm{S} 1$ & $9(81.8)$ & $2(18.2)$ & $7(58.3)$ & $5(41.7)$ \\
\hline $\mathrm{L} 4 / 5 / \mathrm{S} 1$ & $15(71.4)$ & $6(28.6)$ & $14(58.3)$ & $10(41.7)$ \\
\hline \multicolumn{5}{|l|}{ HLD type } \\
\hline Protrusion & $58(67.4)$ & $28(32.6)$ & $48(55.8)$ & $38(44.2)$ \\
\hline Extrusion & $3(60.0)$ & $2(40.0)$ & $3(60.0)$ & $2(40.0)$ \\
\hline \multicolumn{5}{|l|}{ HLD zone } \\
\hline Central & $34(81.0)$ & $8(19.0)$ & $26(61.9)$ & $16(38.1)$ \\
\hline Subarticular & $24(63.2)$ & $14(36.8)$ & $23(60.5)$ & $15(39.5)$ \\
\hline Foraminal & $3(33.3)$ & $6(66.7)$ & $4(44.4)$ & $5(55.6)$ \\
\hline Extraforaminal & $0(0)$ & $2(100)$ & $0(0)$ & $2(100)$ \\
\hline \multicolumn{5}{|l|}{ HLD volume } \\
\hline Mild & $9(56.2)$ & $7(43.8)$ & $25(61.0)$ & $16(39.0)$ \\
\hline Moderate & $23(67.6)$ & $11(32.4)$ & $17(50.0)$ & $17(50.0)$ \\
\hline Severe & $29(70.7)$ & $12(29.3)$ & $9(56.2)$ & $7(43.8)$ \\
\hline \multicolumn{5}{|l|}{ Nerve root - HLD } \\
\hline No contact & $8(80.0)$ & $2(20.0)$ & $7(70.0)$ & $3(30.0)$ \\
\hline Contact & $10(62.5)$ & $6(37.5)$ & $8(50.0)$ & $8(50.0)$ \\
\hline Displacement & $10(33.0)$ & $6(37.5)$ & $8(50.0)$ & $8(50.0)$ \\
\hline Compression & $33(67.3)$ & $16(32.7)$ & $28(57.1)$ & $21(42.9)$ \\
\hline \multicolumn{5}{|l|}{ Disc height loss } \\
\hline None & $9(69.2)$ & $4(30.8)$ & $16(51.6)$ & $15(48.4)$ \\
\hline Less than half & $30(63.8)$ & $17(36.2)$ & $26(55.3)$ & $21(44.7)$ \\
\hline More than half & $22(71.0)$ & $9(29.0)$ & $9(69.2)$ & $4(30.8)$ \\
\hline \multicolumn{5}{|l|}{ Disc degeneration } \\
\hline Grade $1,2,3$ & $14(63.6)$ & $8(36.4)$ & $12(54.5)$ & $10(43.5)$ \\
\hline Grade 4, 5 & $47(68.1)$ & $22(31.9)$ & $39(56.5)$ & $39(56.5)$ \\
\hline
\end{tabular}

Values are presented as number (\%).

HLD, herniated lumber disc; VAS, visual analogue scale; RMDQ, Roland Morris Disability Questionnaire.

was not comparable due to the small number of patients. No significant difference in the therapeutic effect was observed between the central zone and the subarticular zone on the RMDQ, but only $12 \%$ of the foraminal zone cases showed a positive response to the CESI compared to those in the central zone ( $\mathrm{p}=0.036)$. The treatment effect of the CESI was likely to be lower at the edge of the central zone than at the center of the zone.

More protrusion (94.5\%) HLDs than extrusion HLDs were observed, and many of the patients had a severely herniated disc. The HLD volume results were 'mild' (17.5\%), 'moderate' (37.5\%), and 'severe' (45.0\%). The relationship between the nerve and HLD tended to be 'compressed' (53.8\%), followed by 'contact' (17.6\%), 'displaced' (17.6\%), and 'no contact' (11.0\%). Approximately $65 \%$ of $\mathrm{L} 4 / 5,12.1 \%$ of L5/S1, and $23.1 \%$ of L4/5 and L5/ S1 contained the HLDs, demonstrating that L4/5 was more likely to have an HLD. Patient ages were grouped into 10 -year periods, and no differences in effectiveness of the CESI were observed between the age groups. The 
duration of the pain, categorized into 'acute' ( $<1$ month), 'subacute' (1-6 months), and 'chronic' pain ( $>6$ months), had no relationship with effectiveness of the CESI.

\section{DISCUSSION}

The results showed that many of the patients with HLDrelated lumbar radicular pain had a centrally-herniated disc and that central HLDs were more likely to be cured by CESI treatment. However, MRI did not detect any other significant factors to predict the effectiveness of CESI treatment. The number of patients with a HLD in the central zone or the subarticular zone was relatively larger than those with a HLD in the foraminal and extraforaminal zones. The probabilities for an HLD to be positioned in the central, subarticular, foraminal, and extraforaminal zones were $46 \%, 41 \%, 10 \%$, and $2 \%$, respectively [13]. This result was supported by a previous study reporting that an HLD closer to the edge is less likely to migrate, and the migration rates of the central, paracentral, subarticular, foraminal, and extraforaminal zones were $17.3 \% 74.2 \%$, $4.3 \%, 2.5 \%$, and $1.8 \%$, respectively. As a disc degenerates and displaces, intradiscal pressure remains high; hence, the disc is pushed out to the posterolateral edge with less resistance, rather than being reduced spontaneously by the posterior longitudinal ligament [14]. Consequently, central protrusion appeared relatively more often than posterolateral protrusion, which means it has better accessibility to CESI treatment.

We used a $30-\mathrm{mL}$ volume to reduce pain. A $20-\mathrm{mL}$ volume ensures that the epidural space is filled to at least L5/S1 in $91.7 \%$ of the cases, suggesting that the USguided approach is appropriate for CESI [4]. In contrast, Kelman [15] observed patients going into shock after injecting $50 \mathrm{~mL}$ normal saline into the epidural space. The injected fluid caused a washout effect of regional inflammatory mediators and blocked nociceptive C-fiber conduction due to the steroid [16]. The distribution of solution in the epidural space follows a cephalad direction of least resistance [17]. The positioning of the patient allows the injectate to accumulate on the dependent side because of gravity. Laying a patient on the side of their leg pain after a CESI has a beneficial effect on the degree of pain relief [18]. An incorrectly advanced needle toward the opposite side of the lesion results in a diminished therapeutic effect [4]. That is why the CESI for centrally located HLD is less affected by positioning and incorrect needle direction and a centrally located herniated disc has a better outcome after CESI.

The number of VAS-responders was twice as large as that of VAS-non-responders (61 responders and 30 nonresponders). The differences in CESI effects measured by the RMDQ were insignificant, although there were more RMDQ-responders than RMDO-non-responders (51 responders and 40 non-responders). This result may have occurred because a larger volume in a herniated disc is likely to have better resolution due to the larger neovascular supply, and the size is sufficiently reduced by conservative treatment; thus, reducing the impact of the CESI [19].

Furthermore, radicular pain can be aroused not only by mechanical compression but also by inflammatory factors formed by HLDs, such as nitric oxide, prostaglandin $\mathrm{E}_{2}$, and interleukin 6 [3], which could explain the insignificant differences in terms of the nerve root relationship with HLD.

The treatment effect seemed to have no relationship with disc height loss or disc degeneration, which are MRI findings linked to aging. Young patients are likely to have more nucleus pulposus components in their HLDs, inducing more radicular pain by inflammation; hence, resulting in more of a response to steroid [20], whereas the amount of nucleus pulposus components tends to diminish in older patients resulting in mechanical compression problems caused by the annulus fibrosus. The observation that disc height loss and disc degeneration do not directly cause mechanical compression and inflammation to the dura could also be an explanation for their lack of a significant impact on CESI effectiveness.

We examined the remedial effects of CESI before and after treatment using a VAS [21] and the RMDQ to measure functional disability status [22] with high objectivity in the results, although the examination depended on subjective patient statements. The categories of 'responder' and 'non-responder' was based on the minimal improvement cutoff of $50 \%$ for conservativeness of the results [23]

A limitation of this retrospective study was the short follow-up of $<6$ weeks based on the observation that a CESI is more effective in the short-term [24]. Additionally, other environmental and psychological causes of pain were not considered, and the use of traction, physical therapy 
modalities, or medications were not considered. An additional limitation was that a variety of different substances (normal saline, steroid, and local anesthetic) were used. This made it difficult to conclude whether pain relief was because of the steroid, a larger volume, or a combination of both.

According to our results, the HLD zone on MRI was a significant area for pain reduction after CESI. A centrally located HLD was a good outcome predictor for CESI addressing low back pain.

\section{CONFLICT OF INTEREST}

No potential conflict of interest relevant to this article was reported.

\section{REFERENCES}

1. Nygaard OP, Mellgren SI, Osterud B. The inflammatory properties of contained and noncontained lumbar disc herniation. Spine (Phila Pa 1976) 1997;22:2484-8.

2. Franson RC, Saal JS, Saal JA. Human disc phospholipase A2 is inflammatory. Spine (Phila Pa 1976) 1992; 17(6 Suppl):S129-32.

3. Olmarker K, Blomquist J, Stromberg J, Nannmark U, Thomsen P, Rydevik B. Inflammatogenic properties of nucleus pulposus. Spine (Phila Pa 1976) 1995;20:665-9.

4. Park Y, Lee JH, Park KD, Ahn JK, Park J, Jee H. Ultrasound-guided vs. fluoroscopy-guided caudal epidural steroid injection for the treatment of unilateral lower lumbar radicular pain: a prospective, randomized, single-blind clinical study. Am J Phys Med Rehabil 2013;92:575-86.

5. Hopwood MB, Abram SE. Factors associated with failure of lumbar epidural steroids. Reg Anesth 1993; 18:238-43.

6. Sayegh FE, Kenanidis EI, Papavasiliou KA, Potoupnis ME, Kirkos JM, Kapetanos GA. Efficacy of steroid and nonsteroid caudal epidural injections for low back pain and sciatica: a prospective, randomized, doubleblind clinical trial. Spine (Phila Pa 1976) 2009;34:1441-7.

7. Wewers ME, Lowe NK. A critical review of visual analogue scales in the measurement of clinical phenomena. Res Nurs Health 1990;13:227-36.

8. Roland M, Morris R. A study of the natural history of back pain. Part I: development of a reliable and sen- sitive measure of disability in low-back pain. Spine (Phila Pa 1976) 1983;8:141-4.

9. Roland M, Morris R. A study of the natural history of low-back pain. Part II: development of guidelines for trials of treatment in primary care. Spine (Phila $\mathrm{Pa}$ 1976) 1983;8:145-50.

10. Fardon DF. Nomenclature and classification of lumbar disc pathology. Spine (Phila Pa 1976) 2001;26:461-2.

11. Pfirrmann CW, Dora C, Schmid MR, Zanetti M, Hodler J, Boos N. MR image-based grading of lumbar nerve root compromise due to disk herniation: reliability study with surgical correlation. Radiology 2004;230:583-8.

12. Pfirrmann CW, Metzdorf A, Zanetti M, Hodler J, Boos N. Magnetic resonance classification of lumbar intervertebral disc degeneration. Spine (Phila Pa 1976) 2001;26:1873-8.

13. Daghighi MH, Pouriesa M, Maleki M, Fouladi DF, Pezeshki MZ, Mazaheri Khameneh R, et al. Migration patterns of herniated disc fragments: a study on 1,020 patients with extruded lumbar disc herniation. Spine J 2014;14:1970-7.

14. Cyriax JH. Textbook of orthopaedic medicine. London: Bailliere Tindall; 1882.

15. Kelman H. Epidural injection therapy for sciatic pain. Am J Surg 1944;64:183-90.

16. Kantrowitz F, Robinson DR, Mcguire MB, Levine L. Corticosteroids inhibit prostaglandin production by rheumatoid synovia. Nature 1975;258:737-9.

17. Nishimura N, Fujimaki T, Oshibuchi M, Yoshikawa I, Aida M. The distribution of solutions in the epidural space. Masui 1991;40:350-60.

18. Makki D, Nawabi DH, Francis R, Hamed AR, Hussein AA. Is the outcome of caudal epidural injections affected by patient positioning? Spine (Phila Pa 1976) 2010;35:E687-90.

19. Komori H, Shinomiya K, Nakai O, Yamaura I, Takeda S, Furuya K. The natural history of herniated nucleus pulposus with radiculopathy. Spine (Phila Pa 1976) 1996;21:225-9.

20. McCarron RF, Wimpee MW, Hudkins PG, Laros GS. The inflammatory effect of nucleus pulposus. A possible element in the pathogenesis of low-back pain. Spine (Phila Pa 1976) 1987;12:760-4.

21. Price DD, McGrath PA, Rafii A, Buckingham B. The validation of visual analogue scales as ratio scale 
measures for chronic and experimental pain. Pain 1983;17:45-56.

22. Grotle M, Brox JI, Vollestad NK. Concurrent comparison of responsiveness in pain and functional status measurements used for patients with low back pain. Spine (Phila Pa 1976) 2004;29:E492-501.

23. Ostelo RW, Deyo RA, Stratford P, Waddell G, Croft P, Von Korff M, et al. Interpreting change scores for pain and functional status in low back pain: towards international consensus regarding minimal important change. Spine (Phila Pa 1976) 2008;33:90-4.

24. Abdi S, Datta S, Trescot AM, Schultz DM, Adlaka R, Atluri SL, et al. Epidural steroids in the management of chronic spinal pain: a systematic review. Pain Physician 2007;10:185-212. 